\title{
Effectiveness of community based health education intervention about safe motherhood among pregnant females in Sharkia Governorate, Egypt
}

\author{
Eman M. Mortada, Omnia S. EI Seifi and Huny Bakry \\ Public Health and Preventive Medicine Department, Faculty of Medicine, Zagazig \\ University, Egypt
}

\begin{abstract}
Background: knowledge about safe motherhood practices could help not only to reduce pregnancy related health risks but also helps in improving maternal and child health. Aim: The aim of our study was to measure the effectiveness of health education intervention on the knowledge and attitude of different safe motherhood domains among pregnant women. Methods: a community based interventional study was conducted on 122 pregnant women in El- Nakhas village, Sharkia Governorate over a period of 6 months using structured questionnaire asking about the knowledge and attitude towards antenatal, natal, post natal care, breastfeeding and family planning. Results: Our results revealed significant improvement in the total knowledge and attitude score regarding; antenatal care (from $13.80 \pm 3.47$ to $21.96 \pm 4.32$ ) and (from $11.26 \pm 1.20$ to $12.92 \pm 1.80$ ) respectively, post natal care total score (from 5.62 \pm 0.74 to $9.10 \pm 0.70$ ) and from $(7.68 \pm 1.76$ to $10.86 \pm 2.60$ ) respectively, total Family planning (from $6.88 \pm 1.28$ to $10.86 \pm 1.72)$ and $(5.64 \pm 1.26$ to $6.38 \pm 2.54)$ respectively, Breast feeding total score (from $16.92 \pm 2.30$ to $22.42 \pm 2.74$ ) and (from $6.82 \pm 1.44$ to $9.30 \pm 1.52$ ) respectively. The age and education of the participants were the main factors affecting the post interventional knowledge. Conclusion: Health education intervention succeeded in improving the knowledge and attitude of safe motherhood different domains. Rural women need continuous health education programs about safe motherhood for improving their knowledge and attitude.
\end{abstract}

Key words: safe motherhood, knowledge, attitude, pregnant women, intervention

\section{Introduction}

Although there has been considerable improvement in maternal health globally, it is increasingly evident that important gaps and disparities remain. Improving both maternal and child health are among the eight goals of the MDGs and its progress towards improving maternal health and reducing mortality is specifically lagging behind. Globally, more than half a million women die every year due to complications of pregnancy and childbirth and an estimated 10 million mothers experience severe consequences related to childbirth ${ }^{(1)}$. Maternal mortality in Egypt is still relatively high, and the country faces challenges in reducing it further. Recent evidence suggests that a woman's lifetime risk of dying from maternal causes in Egypt has 
dropped dramatically, from 82 in 100,000 in 1990 to 5.5 in $2008^{(2)}$. The current level puts Egypt in about the middle among countries in the region. Maternal deaths, largely avoidable, are strongly associated with the absence of good medical care before, during, or after delivery. Safe motherhood is defined in this study as proper antenatal, natal and postnatal care thus ensuring that all women receive the care they need to be safe and healthy throughout pregnancy and childbirth ${ }^{(3)}$.

Community-based interventions can effectively tackle maternal, newborn and child health problems as decisions to seek and access health services are strongly influenced by socio-cultural norms ${ }^{(4)}$. Ample evidence indicates that when women have greater knowledge through education, there is greater likelihood that they will have better pregnancy and delivery outcomes ${ }^{(5,6)}$. This is likely because acquiring knowledge through education equips women to make appropriate decisions about their health, including during pregnancy and childbirth. A better informed woman is more likely to make appropriate decisions during obstetric emergencies, which was adopted in developed countries to decrease morbidities and mortalities related to pregnancy and puerperium. ${ }^{(7,8)}$, but many developing countries have women with poor education which is more prevalent in rural communities ${ }^{(9,10)}$. So we aimed to assess the knowledge and awareness about safe motherhood practices among pregnant to help in the future reducing of pregnancy related health risks and promote safer pregnancies and deliveries.

\section{Objectives:}

1- To measure the knowledge level related to safe motherhood domains among pregnant women

2- To assess the current participants' attitude.

3- To implement a health education intervention.

4- To evaluate the effectiveness of applied intervention on knowledge and attitude regarding safe motherhood.

\section{Methodology}

Study design and setting: an interventional community based study was carried out to fulfill the objectives of the study using pre-post designs during the period from August 2014 to January 2015. Data were collected from the studied groups before and after the intervention by about 3 months.

Target population and sampling: the target group for this study was pregnant females attending antenatal care clinic in a PHC unit in Zagazig district. The sample size was calculated using Epi info version 6 software program assuming that the change of knowledge can reach up to $33 \%$, according to the findings from our pilot study, at a confidence level $(95.0 \%)$ and the power of the test $(80.0 \%)$, the calculated sample size was 66. As we are using a multistage just one omit was selected o sampling, we doubled the sample to be 132 , in addition to $10 \%$ expected non response from the participants, the final sample was (145). Multistage random sampling technique was used to select the participants, where out of 17 districts of Sharkia Governorate, Zagazig district was randomly selected, then out of 38 primary health care units in Zagazig district, one unit was randomly selected and taken as a cluster "El- Nakhas village". To collect our data and one 
specific day of antenatal care visits was randomly selected to visit the health unit weekly. As participation was voluntary after excluding females who did not agree to participate in the study, a sample of (122) female who met the inclusion criteria (married females between 16-49 years old and pregnant) were included in our study with a response rate $(84.1 \%)$.

\section{Study tools:}

\section{Tools for data collection:}

1- Questionnaire used for data collection:

The final format of the structured questionnaire was thoroughly pre-tested, modified and edited to suit our culture on the basis of feedback received from the pilot study. Improvements of the questionnaire consisted mainly of: simplifying the language, shortening sentences in addition the unclear items were clarified and modified in order to be easily understood by participants and to facilitate its comprehension. The pilot tested 15 females were excluded from the final analysis.

The used questionnaire is divided into four parts:

$>$ The $1^{\text {st }}$ part to assess sociodemographic characteristics (which includes questions about age, marital status, education level and occupation of the study participants).

$>$ The $2^{\text {nd }}$ part to assess the participants' obstetric history (which includes questions about number of deliveries i.e. parity, and if there were complications during the current pregnancy and delivery).

$>$ The $3^{\text {rd }}$ part to measure knowledge and attitude about safe motherhood main domains which includes questions about:

- Ante Natal Care (ANC): knowledge about the benefits of ANC visits, importance of ANC during $1^{\text {st }} 3$ months of pregnancy, maternal danger signs, administration of iron supplementations and tetanus toxoid and the attitude and intentions to go through these in the next pregnancy.

- Postnatal Care: Include questions assessing the knowledge about the benefits of delivering at a health facility, the importance of postnatal care for mothers and infants and their attitudes towards postnatal care.

- Family Planning: knowledge about the meaning of family planning, role of breastfeeding and the importance of husband's role in taking the decision about family planning, also their attitudes to use family planning methods and the attitude of husbands about that, and also included questions about the types of modern family planning methods.

- Breast Feeding: This section includes questions assessing the knowledge about exclusive breastfeeding, the advantages of breastfeeding for mother and infants, the good practice of breast feeding in term of the starting time, and also their attitudes towards breastfeeding ${ }^{(11)}$.

The total number of questions was 32 (19 questions to assess the knowledge and 13 questions to assess the attitude). In the knowledge section, multiple answer 
choices were presented for each question, where each correct answer took 1 mark while wrong or don't know took 0 mark. This gave a total score range of $0-76$ for knowledge section. The response of the attitude was measured along a Likert scale which consists of 5 point scale: (0: strongly disagree, 1: disagree, 2: neutral, 3: agree and 4: strongly disagree) which gave a total scare range of (0-52).

$4^{\text {th }}$ part to take an overview about the antenatal care services provided during the current pregnancy inside in PHC, including; the information they got about " the importance of rest, the drugs that should be avoided during pregnancy and the diet they must consume ", the methods tools for information delivery, assessment and the physician about it, blood analysis for iron, if the physician gave them any comment about their laboratory investigations and if the got vitamins from the health units.

\section{Intervention tool:}

Educational sessions with poster to help us achieve the desired improvements in knowledge and attitude of the targeted females.

\section{Phases of the intervention}

A- Pre-intervention (baseline study): Testing of the questionnaire was done among a group of 15 females and all the required corrections were done. A faceto-face interview was also done among this group of females in order to know the level of their knowledge, gap areas and their opinion about safe motherhood items in order to guide us in formulating our health education messages.

B- Intervention phase (Health education sessions):

All the sampled females received educational intervention sessions based on the standard safe motherhood guidelines as documented within the Safe Motherhood Initiative Demand Side (SMID) manual ${ }^{(12)}$

- The used educational methods were lectures demonstrated by PowerPoint followed by open group discussions. The educational program was applied and repeated among small group of (10-15) females.

\section{C- Post intervention (evaluation phase):}

For evaluating the effectiveness of the educational intervention, 3 months later a post-test questionnaire identical to preliminary questions in the pre-test one was used.

Outcomes Measured: changes in knowledge, and attitude of the sampled females regarding the different domains of motherhood.

\section{Data management and analysis}

After the study was completed the collected data were recorded, then presented and analyzed by using SPSS (Statistical Package for the Social Sciences) version $19.0^{(13)}$. The analyses were done using mean and standard deviation for both knowledge and attitude and paired $t$ test was used to assess the difference between mean scores of the total knowledge and attitude before and after the intervention. Linear regression analysis was conducted to identify the factors 
predicting the knowledge regarding motherhood domains. Statistical significance was considered at $\mathrm{p}$-value $<0.05$

\section{Ethical consideration:}

The required official permissions were obtained before carrying out the study from the ministry of health and population. Participation was voluntary and those who agree to participate gave written consent after being informed about the objectives of the study and importance of the research. Participants were assured about the confidentiality of the given information and that the study results would be used only for the purpose of research and participants' identity kept anonymous and the questionnaires were numerically coded.

\section{Results}

The total number of the female under study was 122 , their mean age was 27.2 \pm 6.1 , age at $1^{\text {st }}$ pregnancy $20.6 \pm 2.5$, at mean month of gestation $7.9 \pm 0.8$, the majority of them have intermediate education, $74.6 \%$, not working $82.0 \%$, having 1-2 children $64.8 \%$ with interpregnancy pace $>2$ years $53.3 \%$ and not suffering from any disease $71.3 \%$. Table (1).

Comparing the mean knowledge score about items of antenatal care among the studied females revealed an increase in their knowledge score from the preintervention to the post-intervention except for the signs of high risk pregnancy. Regarding their attitude toward antenatal care it shows significant improvement except for taking medications. The total Knowledge and attitude scores regarding antenatal care show highly significant improvement from pre to post intervention $(\mathrm{P}<0.001)$. Table (2).
Comparing the mean knowledge and attitude scores about items of postnatal care among the studied females revealed a significant increase in their scores from the pre-intervention to the postintervention regarding all items as well as their total knowledge and attitude scores. $(\mathrm{P}<0.001)$. Table $(3)$.

Comparing the mean knowledge and attitude scores about items of family planning among the studied females revealed a significant increase in their scores from the pre-intervention to the post-intervention regarding all items as well as their total knowledge and attitude scores. $\quad(\mathrm{P}<0.001)$, except for their attitude regarding husband support. $(p=0.06)$. Table (4).

The mean knowledge and attitude score regarding breast feeding among the studied females revealed a significant increase from the pre-intervention to the post-intervention regarding all items as well as their total knowledge and attitude scores. $(\mathrm{P}<0.001)$, except for their knowledge and attitude regarding exclusive breastfeeding for $1^{\text {st }} 6$ months $(p>0.05)$. Table (5).

The score percentage of the total knowledge and total attitude before and after health education intervention among the studied females was illustrated in Figure (1); where the total knowledge changed from $50.5 \%$ to $93.8 \%$ and total attitude changed from $35.3 \%$ to $66.5 \%$.

The hormonal methods of contraception (pills and injections) were the most common family planning methods used by the studied females $(63.2 \%)$, followed by intrauterine devices $(27.0 \%)$ and lastly other methods $(9.8 \%)$ Figure (2). 
The source of the previous knowledge of the females about items of motherhood was mainly from primary health care doctors $(83.0 \%)$, followed by relatives $(15.4 \%)$ then private doctors(1.6\%) Figure (3).

Table (6) shows the evaluation of the antenatal care services in the primary health care unit, where the most common information they received was about drugs prohibited during pregnancy $91.0 \%$, all received the information through face to face direct interview (100.0\%), most of them didn't measure their weights in every antenatal visit $(73.0 \%)$ and didn't receive any comment about their weights $(82.8 \%)$, the majority of them didn't undergo blood analysis $(63.2 \%)$ and were not inform about the results (77.0\%) and lastly, only $36.9 \%$ of them got vitamins from the unit.

Type of Regression analysis revealed that the age, years of education of the females were the only significant independent predictor for total post intervention knowledge among the studied group, Table (7).

\section{Discussion}

Safe motherhood means ensuring that all women receive the care they need to be safe and healthy throughout pregnancy and childbirth ${ }^{(14)}$. Knowledge about safe motherhood practices could help reduce pregnancy related health risks. Health education and increased knowledge of mothers in relation to their health is a strategy of choice adopted in many countries for improving maternal and child health $^{(15)}$ This intervention was conducted among 122 pregnant women to improve their knowledge and attitude about safe motherhood.

\section{Antenatal Care Knowledge and attitude}

Good care during pregnancy is important for maternal health and fetal development, increasing the chance of having a skilled attendant at birth and contributes to favorable pregnancy outcome. ${ }^{(16)}$

Our study revealed a significant improvement in knowledge about ANC occurred in the post test evaluation, which was reflected on the improvement of their attitude; this was in accordance with a study conducted in Indonesia and another study in Kenya $(17,18)$ which recorded a significant improvement in ANC knowledge. Our improvement was highly observed in their knowledge about the importance of the ANC visit during 1st 3 months of pregnancy and the importance of iron supplementation and tetanus toxoid. The improvement in the knowledge about the importance of the first visit in the first trimester was supported by the results of another study conducted in Eretria ${ }^{(19)}$ which revealed an improvement in the knowledge and proved by more use of any ANC and more first visits earlier in pregnancy.

The knowledge of our participants was below average about the importance of iron supplementation in the pretest, which was in contrary to a study conducted in an urban area in India ${ }^{(20)}$ which recorded good knowledge about the importance of iron supplementation, this may be due to that our study was conducted in a rural area in which most of our participants have low to intermediate education and they have wrong beliefs that iron weakens the pregnant female body as discovered from face to face interview before the intervention.

The knowledge about tetanus toxoid vaccination was in average in the pretest, 
this may be due to the fact that all our sampled females were already obligatory vaccinated in their routine immunization schedule against tetanus while they were children. Because of the effectiveness of the routine vaccination through the expanded program of immunization (EPI) in Egypt, no one pay attention to that point since a long time as 5 dose tetanus immunization schedule proposed by WHO for pregnant non vaccinated female previously is mandatory as well as most of the physicians nowadays depend on that most of the pregnant females get labor and natal care in hospitals and health care facilities with sterilized instruments, which lower risk of tetanus infection.

Although the knowledge about high risk pregnancy shows improvement from pretest to posttest, there is insignificant change which was in contrary to a study conducted in Nigeria where the improvement was significant ${ }^{(11)}$. Our results may be attributed to that the percentage of our females with risk factors (having diseases, interpregnancy space less than 1 year or elderly) was low, the multiple criteria of the high risk pregnancy together with high percentage of females with intermediate to low educational level may hinder the required improvements. This necessitates more education for our pregnant females about this point.

\section{Post natal care knowledge and attitude}

Mothers and their newborns are vulnerable to illnesses and deaths during getting births and the first $48 \mathrm{~h}$ after delivery. Thus, natal and postnatal care (PNC) is important for both the mother and the child to avoid complications arising from the delivery, as well as to provide the mother with important information. ${ }^{(21)}$ The high score of knowledge in our study about the importance of getting labor in hospitals and health care facilities among the studied females in the pretest reflects the high awareness about its importance among all populations even in rural community and low educated females. This high level of awareness was reflected on the concept of the importance of postnatal examination of the mother and the baby in the posttest. These results were in contrary to another study conducted in Ethiopia where also the concept about importance of postnatal care for mothers was deficient. ${ }^{(22)}$ Nevertheless, obvious improvement was observed in the importance of seeking postnatal medical care specially for the baby in the post test which was reflected on the attitude of the sampled females to be examined postnataly by a health care professional as well, as their babies.

\section{Family planning}

Family planning is one of the important motherhood's care for improving mother's health, preventing exposure to risky pregnancy and improving family life. ${ }^{(23)}$ The knowledge and the attitude of the studied sample about the basic concepts of family planning and using family planning methods were on average in the pretest and much improved in the posttest which reflects the great understanding of them specially about that the religious beliefs aren't against the use of family planning methods as well as their great concern to hear about family planning reflect their readiness for more further improvement about that issue. Our results were supported by studies conducted in 
northen Nigeria and Turkey ${ }^{(24,25)}$ which reflect the same results.

In Eastern culture (mainly in rural areas) the husband is being the dominant member who plays the pivotal role in approving the family size and contraceptive practices, also the social support of husbands is associated with increasing women's contraceptive use. ${ }^{(26)}$ So it was important to explore his role in supporting the use of contraceptive methods, there was adequate scores in husbands opinion about contraception, which reflects good understanding and cooperation from their husband regarding this important point. It was important for us to promote and ensure partner communication around family planning and contraceptive methods as well as enhancing female's confidence in their reproductive decision making.

The most commonly used contraceptive method was hormonal ones which was in accordance with a study conducted in south Jordan ${ }^{(27)}$ revealed that the oral contraceptives was the most frequently used in their study as most of the married do not prefer other methods due to perceived side effects, such as prolonged menstruation, men's concerns about genital sores, also it as important for us to be sure hat the females weren't depend on breast feeding as a method of contraception which isn't an effective one.

\section{Breast feeding}

Breastfeeding is important for growth, immunity and prevention of illness in young infants. Conversely, lack of it is associated with high infant mortality and morbidity from malnutrition and infections. ${ }^{(28)}$ Our results revealed good knowledge about the importance of breastfeeding in the pretest this may be because of the tradition which is still present in the rural community which favors the breast feeding over artificial one, as well as most of our females were house wives which give them more time and chance for breast feeding.

The improvement in the mean knowledge and attitude score of the sampled females within each domain of the motherhood domain together with the obvious improvement in the total knowledge and attitude score reflects the affirmative effect of the educational intervention

Regarding the source of the participants' knowledge about safe motherhood was mainly from primary health care doctors through direct interviews this was supported by a study conducted in Nigeria $^{(29)}$ which stated that their participants acquired their information of safe motherhood practices from health talks and discussions in health facilities which ensure more accurate knowledge and sound information more than other sources. On the other hand, most of our participants didn't measure their weights (in spite of the presence of the weight scale), receive vitamins from the units or under go blood analysis. This was in contrary to another study conducted in Pakistan $^{(30)}$, which stated that these are conducted as routine. This may reflect the scarcity of resources within the facility.

Health knowledge is considered as one of the key factors that enable women to be aware of their health status and improve their acceptance to utilize the available reproductive health services and influence their attitude and future practice $^{(31)}$. In our study; increasing age and years of education were important positive predicting factors which help to 
improve the knowledge of females due to much experience and awareness with increasing age or from previous deliveries as well as the strong effect of higher level of education which is believed to influence the understanding of health messages and the ability to make decisions regarding their health, this was the same as the result of other similar studies in Nigeria and china $(11,31)$.

Conclusion and recommendations: This study reported average knowledge and attitude regarding antenatal care , post natal care, family planning and breast feeding among rural women . Health education intervention showed considerable improvement in the knowledge and attitude regarding different domains of safe motherhood. These findings suggest the need for targeted health education using various educational methods for rural women specially the young mothers and lower educated ones. Healthcare providers, educators and policy makers can use these insights, to develop strategies and further investigation assessing the health service needs of rural women.

\section{References}

1) UNICEF. (2008). Progress for Children: A Report Card on Maternal Mortality (No. 7) (pp. 45). http://www.childinfo.org/files/progre ss_for_children_maternalmortality.p df

2) Wilmoth J. et al. A New Method for Deriving Global Estimates of Maternal Mortality: Supplemental Report: on behalf of the UN Maternal Mortality Estimation InterAgency Group (MMEIG), May 29, 2012
3) Nasreen H, Imam N, Akter R. Safe Motherhood promotion project in Narsingdi District 2006. Research and Evaluation Division, (BRAC) in cooperation with Japan International Cooperation Agency

4) Elder J, Ayala G, Harris S. Theories and intervention approaches to health-behavior change in primary care. Am J Prev Med 1999; 17:275-284.

5) Harrison KA. Childbearing, health and social priorities: a survey of 22,774 consecutive births in Zaria, Northern Nigeria. $\mathrm{Br} \quad \mathrm{J}$ Obstet Gynaecol 1985;92(suppl 5):1-119.

6) Harrison KA: The importance of the educated healthy woman in Africa. Lancet 1997; 349:644-647.

7) Jammeh A, Sundby $J$ and Vangen S. Barriers to emergency obstetric care services in perinatal deaths in rural gambia: a qualitative in-depth interview study. ISRN Obstet Gynecol. 2011;981096.

8) Mushi D, Mpembeni R and Jahn

A. Knowledge about safe motherhood and HIV/AIDS among school pupils in a rural area in Tanzania. BMC Pregnancy Childbirth 2007; 7:5.

9) Sharma M: Knowledge, attitude and belief of pregnant women towards safe motherhood in a rural Indian setting. Social Sciences Directory 2012;1:1. ( accessed 7\9\2014)

10) Roth DM and Mbizvo MT . Promoting safe motherhood in the community: the case for strategies that include men. Afr J Reprod Health 2001; 5(2):10-21

11) Okereke et al. Knowledge of safe motherhood among women in rural communities in northern Nigeria: implications for maternal mortality 
reduction. Reproductive Health 2013;10:57.

12) World Health Organization (WHO). The Safe Motherhood Initiative and beyond. Bull World Health Organ 2007; 85:10. http://www.who.int/bulletin/volumes /85/10/07-045963/en/ (Accessed 2-82014).

13) IBM. IBM SPSS Statistics 19 Core System Users' Guide. Chicago: SPSS Inc.; 2010. http://www.IBMSPSS-Statistics-User s-Guide.pdf.

14) Seif N.Y. and Aziz, M.A.: Effect of breast self-examination training program on knowledge, attitude and practice of a group of working women. J Egyptian Nat Cancer Inst 2000; 12(2): 105-120.

15) Soltani MS1 et al. Evaluation of mothers' knowledge in pre- and postnatal preventive care in the Tunisian Sahel. Sante Publique. 1999 Jun;11(2):203-10. [Pub med]

16) WHO. World Health Report 2005. make every mother and child count. 2005.

Geneva, Switzerland: World Health Organization. http://www.who.int/whr/2005/whr 2005_en.pdf

17) Nuraini E1 and Parker E. Improving knowledge of antenatal care (ANC) among pregnant women: a field trial in central Java, Indonesia Asia Pac J Public Health. 2005;17(1):3-8. [Pub med]

18) Ndirangu G1 et al. Using Young Mothers' Clubs to Improve Knowledge of Postpartum Hemorrhage and Family Planning in Informal Settlements in Nairobi, Kenya. .J Community Health. 2015 Jan 14. http://download.springer.com/static/p
df/364/art\%253A10.1007\%252Fs10

900-014-9986

8.pdf?auth66=1424071222 5b54cf9

74d84a8d5f6bd5560134e8016\&ext $=$ .pdf

19) Turan J, Tesfagiorghis $M$, and Polan M. Evaluation Of A Community Intervention For Promotion Of Safe Motherhood In Eritrea.J Midwifery Womens Health. 2011;56(1):8-

17.http://onlinelibrary.wiley.com/doi /10.1111/j.15422011.2010.00001.x/full

20) Laishram J. et al.. Knowledge and Practice of Ante-natal Care in an Urban Area, Indian Medical Gazette — MARCH 2013 http://medind.nic.in/ice/t13/i3/icet1 3i3p101.pdf

21) Abdella A. Maternal mortality trend in Ethiopia. Ethiopian Journal of Health

Development.2010;24(1):115-

212.http://ejhd.uib.no/ejhd-v24sn1/115\%20Maternal\%20Mortality \%20Trend\%20in\%20Ethiopia.pdf

22) Tesfahun F, Worku W, Mazengiya $\mathbf{F}$, and Kifle $M$. Knowledge, Perception and Utilization of Postnatal Care of Mothers in Gondar Zuria District, Ethiopia: A CrossSectional Study. Matern Child Health J. 2014; 18(10): 2341-2351. [Pub med]

23) Allen RH. The role of family planning in poverty reduction. Obstet Gynecol. 2007 ;110(5):999-1002.

24) Abdulrazaq AG, Kabir S, Mohammad NS, Suleiman IH. The effect of educational intervention on family planning knowledge, attitudes, and practices among married women in a military barrack 
in northern Nigeria. Afr $\mathrm{J}$ Reprod Health. 2014;18(1):93-101. [Pub med]

25) Ayaz S, Efe SY. Family planning attitudes of women and affecting factors. J Turk Ger Gynecol Assoc. 2009;10(3):137-41. [Pub med]

26) Samandari G, Ilene $S$ and O'Connell K. The Role of Social Support and Parity in Contraceptive Use in Cambodia. International prespectives on sexual and reproductive health. 2010;36(3): 122-131

http://www.guttmacher.org/pubs/jo urnals/3612210.html

27) Mahadeen A.I. et al.:Knowledge, attitudes and practices towards family planning among women in the rural southern region of Jordan . EMHJ 2012; 18(2) http://applications.emro.who.int/emh j/v18/06/18_6_2012_0567_0572.pdf

28) Kalanda BF, Verhoeff FH, Brabin

BJ. Breast and complementary feeding practices in relation to morbidity and growth in Malawian infants. European Journal of Clinical Nutrition 2006; 60: 401-407. http://www.nature.com/ejcn/journal/ v60/n3/full/1602330a.html

29) Davies-Adetugbo. Promotion of breast feeding in the community: impact of health education programme in rural communities in Nigeria.J Diarrhoeal Dis Res. 1996 ;14(1):5-11. http://www.jstor.org/stable/234985 52? seq=1\#page_scan_tab_contents

30) Alam A, Qureshi A, Adil M and Ali H. Comparative study of Knowledge, Attitude and Practices among Antenatal Care Facilities utilizing and non-utilizing women. J Pak Med Assoc. 2005;55(2):53-6. http://www.jpma.org.pk/full_articl e text.php?article id=574

31) Zhao Q, Kulane A, Gao Y, Xu B. Knowledge and attitude on maternal health care among rural-to-urban migrant women in Shanghai, China. BMC Women's Health 2009;9:5 http://www.biomedcentral.com/1472 $-6874 / 9 / 5$ 
Table (1): Sociodemographic and reproductive history of the studied females

\begin{tabular}{|c|c|c|}
\hline Variables & \multicolumn{2}{|c|}{ mean \pm S.D } \\
\hline Age (years): & \multicolumn{2}{|c|}{$27.2 \pm 6.1$} \\
\hline Age at 1st pregnancy: & \multicolumn{2}{|l|}{$20.6 \pm 2.5$} \\
\hline Gestational age (in months): & \multicolumn{2}{|l|}{$7.9 \pm 0.8$} \\
\hline Educational level: & No (122) & $(\%)$ \\
\hline $\begin{array}{l}\text { - Low (preparatory) } \\
\text { - Intermediate (secondary) } \\
\text { - High (University and above) }\end{array}$ & $\begin{array}{l}22 \\
91 \\
9\end{array}$ & $\begin{array}{l}18.0 \\
74.6 \\
7.4\end{array}$ \\
\hline Years of education: (mean \pm S.D) & \multicolumn{2}{|l|}{$7 \pm 1.2$} \\
\hline $\begin{array}{l}\text { Occupation: } \\
\text { - Housewives } \\
\text { - Working }\end{array}$ & $\begin{array}{l}100 \\
22\end{array}$ & $\begin{array}{l}82.0 \\
18.0\end{array}$ \\
\hline $\begin{array}{c}\text { Number of children: } \\
-\quad 1 \text {-2 children } \\
\bullet \quad>2 \text { children }\end{array}$ & $\begin{array}{l}79 \\
43\end{array}$ & $\begin{array}{l}64.8 \\
35.2\end{array}$ \\
\hline $\begin{array}{c}\text { Inter-pregnancy space: } \\
-\quad<1 \text { year } \\
-\quad 1-2 \text { year } \\
\bullet \quad>2 \text { years }\end{array}$ & $\begin{array}{l}22 \\
35 \\
65\end{array}$ & $\begin{array}{l}18.0 \\
28.7 \\
53.3\end{array}$ \\
\hline $\begin{array}{l}\text { Suffering from diseases: } \\
\text { - None } \\
\text { - Anemia } \\
\text { - Hypertension } \\
\text { - Diabetes }\end{array}$ & $\begin{array}{l}87 \\
24 \\
9 \\
2\end{array}$ & $\begin{array}{l}71.3 \\
19.7 \\
7.4 \\
1.6\end{array}$ \\
\hline
\end{tabular}


Table (2): Mean Knowledge and attitude scores about items of Antenatal care among the studied females before and after the intervention.

\begin{tabular}{|c|c|c|c|}
\hline Items of $\mathrm{ANC}$ & $\begin{array}{l}\text { Pre-intervention } \\
\text { Mean } \pm \text { SD }\end{array}$ & $\begin{array}{l}\text { Post intervention } \\
\text { Mean } \pm \text { SD }\end{array}$ & $* \mathbf{p}$ \\
\hline \multicolumn{4}{|l|}{ Knowledge } \\
\hline $\begin{array}{l}\text { Importance of antenatal care during } \\
\text { Pregnancy }\end{array}$ & $2.40 \pm 1.00$ & $4.00 \pm 0.00$ & $<0.001$ \\
\hline $\begin{array}{l}\text { Importance of antenatal care during } \\
1^{\text {st }} 3 \text { months of pregnancy }\end{array}$ & $1.64 \pm 0.42$ & $3.64 \pm 1.02$ & $<0.001$ \\
\hline Iron supplementations & $1.66 \pm 0.62$ & $3.26 \pm 1.42$ & $<0.001$ \\
\hline Tetanus toxoid importance & $4.30 \pm 1.23$ & $7.22 \pm 1.44$ & $<0.001$ \\
\hline Signs of high risk pregnancy & $3.80 \pm 0.20$ & $3.84 \pm 0.44$ & $* * \mathrm{NS}$ \\
\hline Total ANC knowledge Score & $13.80 \pm 3.47$ & $21.96 \pm 4.32$ & $<0.001$ \\
\hline \multicolumn{4}{|l|}{ Attitude } \\
\hline $\begin{array}{l}\text { Intention to attend antenatal care in } \\
\text { the health unit in the next pregnancy }\end{array}$ & $4.00 \pm 0.00$ & $4.00 \pm 0.00$ & ---- \\
\hline $\begin{array}{l}\text { Intention to attend antenatal care during } \\
1 \text { st } 3 \text { months of the next pregnancy }\end{array}$ & $2.46 \pm 0.60$ & $3.64 \pm 1.00$ & $<0.001$ \\
\hline Intention to take tetanus vaccine & $1.40 \pm 0.20$ & $1.82 \pm 0.40$ & $<0.001$ \\
\hline Intention to take medications & $3.40 \pm 0.40$ & $3.46 \pm 0.40$ & NS \\
\hline Total ANC attitude Score & $11.26 \pm 1.20$ & $12.92 \pm 1.80$ & $<0.001$ \\
\hline
\end{tabular}

** NS=Not Significant 
Table (3): Mean Knowledge and attitude scores about items of postnatal care among the studied females before and after the intervention.

\begin{tabular}{|l|l|l|l|}
\hline Items of post natal care & $\begin{array}{l}\text { Pre-intervention } \\
\text { Mean } \pm \text { SD }\end{array}$ & $\begin{array}{l}\text { Post -intervention } \\
\text { Mean } \pm \text { SD }\end{array}$ & *p \\
\hline Knowledge & \multicolumn{2}{|l|}{} \\
\hline The importance of delivering in a hospital & $2.86 \pm 0.28$ & $4.00 \pm 0.00$ & $<0.001$ \\
\hline $\begin{array}{l}\text { The importance of seeking postnatal medical } \\
\text { care for the baby }\end{array}$ & $1.46 \pm 0.22$ & $2.84 \pm 0.30$ & $<0.001$ \\
\hline $\begin{array}{l}\text { The importance of seeking postnatal medical } \\
\text { care for the mother }\end{array}$ & $1.30 \pm 0.24$ & $2.26 \pm 0.40$ & $<0.001$ \\
\hline $\begin{array}{l}\text { Total post natal care knowledge Score } \\
\text { Attitude }\end{array}$ & $\mathbf{5 . 6 2 \pm 0 . 7 4}$ & $\mathbf{9 . 1 0 \pm 0 . 7 0}$ & $<\mathbf{0 . 0 0 1}$ \\
\hline Intention to deliver in a hospital & $2.28 \pm 0.48$ & $3.24 \pm 0.62$ & $<0.001$ \\
\hline Intention to be examined by PHC health care providers & $1.30 \pm 0.24$ & $1.74 \pm 0.64$ & $<0.001$ \\
\hline Intention to undergo routine postnatal examination & $2.54 \pm 0.62$ & $3.92 \pm 0.84$ & $<0.001$ \\
\hline $\begin{array}{l}\text { Intention to undergo routine postnatal examination for } \\
\text { the baby }\end{array}$ & $1.56 \pm 0.42$ & $1.96 \pm 0.50$ & $<0.001$ \\
\hline Total post natal care attitude Score & & & \\
\hline Paired t test was used & $\mathbf{7 . 6 8} \pm \mathbf{1 . 7 6}$ & $\mathbf{1 0 . 8 6 \pm 2 . 6 0}$ & $<\mathbf{0 . 0 0 1}$ \\
\hline
\end{tabular}


Table (4): Mean Knowledge and attitude scores about items of family planning among studied females before and after the intervention.

\begin{tabular}{|l|l|l|l|}
\hline Items of family planning & $\begin{array}{l}\text { Pre-intervention } \\
\text { Mean } \pm \text { SD }\end{array}$ & $\begin{array}{l}\text { Post -intervention } \\
\text { Mean } \pm \text { SD }\end{array}$ & *p \\
\hline Knowledge & \multicolumn{2}{|l|}{} \\
\hline Meaning of family planning & $2.26 \pm 0.64$ & $3.64 \pm 0.86$ & $<0.001$ \\
\hline Role of Breast feeding in family planning & $2.62 \pm 0.44$ & $3.82 \pm 0.24$ & $<0.001$ \\
\hline $\begin{array}{l}\text { The role of The husband in the decision } \\
\text { about using family planning methods }\end{array}$ & $2.00 \pm 0.20$ & $3.40 \pm 0.62$ & $<0.001$ \\
\hline Total family planning knowledge Score & $\mathbf{6 . 8 8} \pm \mathbf{1 . 2 8}$ & $\mathbf{1 0 . 8 6} \pm \mathbf{1 . 7 2}$ & $<0.001$ \\
\hline Attitude & & & $<0.001$ \\
\hline Intention to use family planning methods & $2.52 \pm 0.44$ & $3.24 \pm 1.6$ & $<0.001$ \\
\hline $\begin{array}{l}\text { Intention of the husband to support the } \\
\text { use of family planning methods }\end{array}$ & $3.12 \pm 0.82$ & $3.14 \pm 0.94$ & $* * \mathrm{NS}$ \\
\hline Total family planning attitude Score & $\mathbf{5 . 6 4 \pm 1 . 2 6}$ & $\mathbf{6 . 3 8} \pm \mathbf{2 . 5 4}$ & $<\mathbf{0 . 0 0 1}$ \\
\hline Ppairedt test was used
\end{tabular}

** NS=Not Significant 
Table (5): Mean Knowledge and attitude scores about items of breast feeding among studied females before and after the intervention.

\begin{tabular}{|c|c|c|c|}
\hline Items of breast feeding & $\begin{array}{l}\text { Pre-intervention } \\
\text { Mean } \pm \text { SD }\end{array}$ & $\begin{array}{l}\text { Post -intervention } \\
\text { Mean } \pm \text { SD }\end{array}$ & $* \mathbf{p}$ \\
\hline \multicolumn{4}{|l|}{ Knowledge } \\
\hline Breast feeding is suitable in all situations & $1.80 \pm 0.20$ & $3.80 \pm 0.40$ & $<0.001$ \\
\hline $\begin{array}{l}\text { Breast feeding must start immediately } \\
\text { after labor }\end{array}$ & $3.26 \pm 0.82$ & $4.00 \pm 0.00$ & $<0.001$ \\
\hline Exclusive breastfeeding for $1^{\text {st }} 6$ months & $4.20 \pm 0.24$ & $4.42 \pm 1.86$ & $* * \mathrm{NS}$ \\
\hline $\begin{array}{l}\text { Benefits of breast feedings for mother } \\
\text { and baby }\end{array}$ & $2.24 \pm 0.42$ & $2.60 \pm 0.28$ & $<0.001$ \\
\hline Problems of artificial feeding & $5.42 \pm 0.62$ & $7.60 \pm 0.20$ & $<0.001$ \\
\hline Total breastfeeding knowledge Score & $16.92 \pm 2.30$ & $22.42 \pm 2.74$ & $<0.001$ \\
\hline Attitude & & & $<0.001$ \\
\hline Intention to Breastfeed her child & $3.42 \pm 1.00$ & $3.78 \pm 1.08$ & $<0.001$ \\
\hline $\begin{array}{l}\text { Intention of immediate start of breastfeeding } \\
\text { after labor }\end{array}$ & $1.92 \pm 0.30$ & $4.00 \pm 0.00$ & $<0.001$ \\
\hline Intention of starting of weaning after 6 months & $1.48 \pm 0.14$ & $1.52 \pm 0.44$ & NS \\
\hline Total breast feeding attitude Score & $6.82 \pm 1.44$ & $9.30 \pm 1.52$ & $<0.001$ \\
\hline
\end{tabular}


Table (6): Antenatal care services provided during the current pregnancy in the PHC (N. 122).

\begin{tabular}{|c|c|c|}
\hline Variables & No. & $\%$ \\
\hline \multicolumn{3}{|l|}{ 1-Getting information about: } \\
\hline -Importance of rest & 63 & 51.6 \\
\hline -Drugs which should be prevented during pregnancy & 111 & 91.0 \\
\hline -Diet during pregnancy & 58 & 47.5 \\
\hline \multicolumn{3}{|l|}{ 2-Tools of information delivery: } \\
\hline -Health education session & 0 & 0.0 \\
\hline -Direct interview & 122 & 100.0 \\
\hline \multicolumn{3}{|l|}{ 3-Weight assessment at every visit: } \\
\hline -Yes & 33 & 27.0 \\
\hline$-\mathrm{No}$ & 89 & 73.0 \\
\hline $\begin{array}{l}\text { 4-Getting advice on weight from the physician: } \\
\text {-Yes }\end{array}$ & & \\
\hline \multirow[t]{2}{*}{$-\mathrm{No}$} & 21 & 17.2 \\
\hline & 101 & 82.8 \\
\hline \multicolumn{3}{|l|}{ 5- Blood analysis for Iron level every visit: } \\
\hline -Yes & 46 & 37.7 \\
\hline$-\mathrm{No}$ & 76 & 63.2 \\
\hline \multicolumn{3}{|l|}{ 6-Informed about laboratory investigation results: } \\
\hline -Yes & 28 & 23.0 \\
\hline$-\mathrm{No}$ & 94 & 77.0 \\
\hline \multicolumn{3}{|l|}{ 7- Get vitamins from the PHC: } \\
\hline -Yes & 45 & 36.9 \\
\hline$-\mathrm{No}$ & 77 & 63.1 \\
\hline
\end{tabular}

\# the answers "yes" were only presented. 
Table (7): Linear regression analysis of variables which significantly predict the total post intervention knowledge of all domains of motherhood among the studied group.

\begin{tabular}{|c|c|c|c|c|c|c|}
\hline \multirow[t]{2}{*}{ Variable } & \multirow[t]{2}{*}{ B } & \multirow[t]{2}{*}{ SE } & \multirow[t]{2}{*}{$\mathbf{t}$} & \multirow[t]{2}{*}{ P value } & \multicolumn{2}{|c|}{$95.0 \% \mathrm{C}$ I interval for $\mathrm{B}$} \\
\hline & & & & & $\begin{array}{l}\text { Lower } \\
\text { bound }\end{array}$ & $\begin{array}{l}\text { Upper } \\
\text { bound }\end{array}$ \\
\hline Constant & 10.905 & 1.190 & 9.164 & 0.00 & 8.548 & 13.263 \\
\hline Age & 0.557 & 0.051 & 10.953 & 0.00 & 0.457 & 0.658 \\
\hline Years of education & 1.920 & 0.216 & 8.889 & 0.00 & 1.492 & 2.348 \\
\hline
\end{tabular}




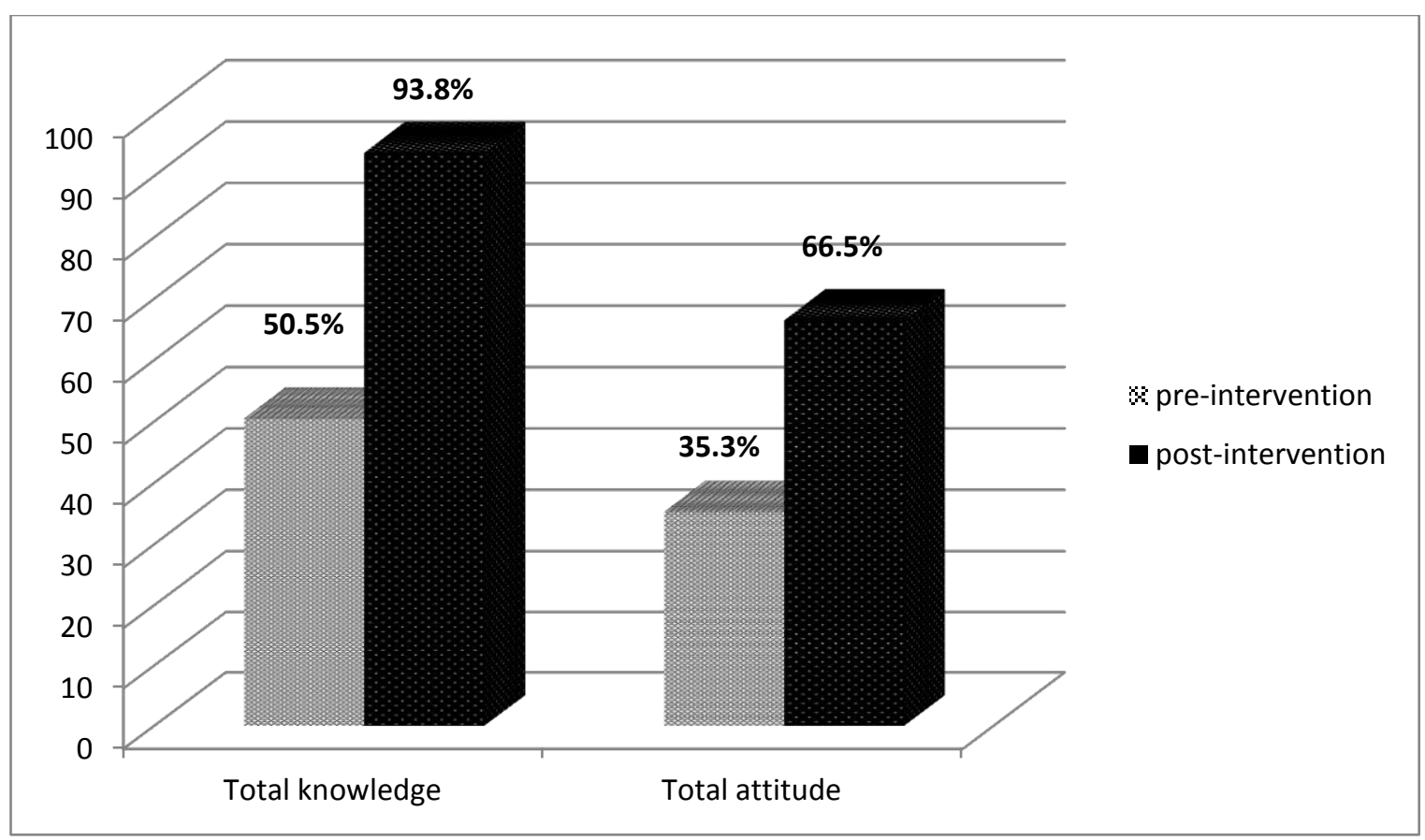

Fig.(1): percents of the total knowledge and total attitude scores before and after health education intervention regarding all domains of motherhood among the studied females.

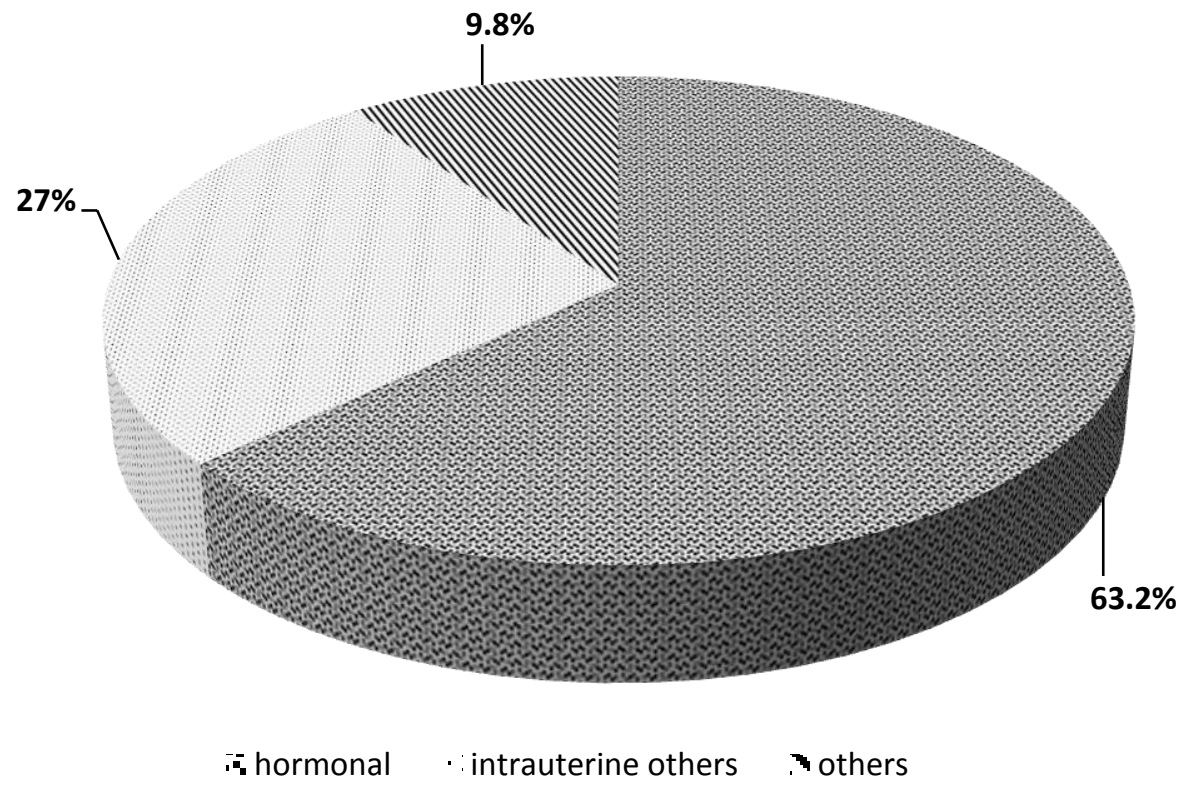

Fig (2): contraceptive methods used by the studied females. 


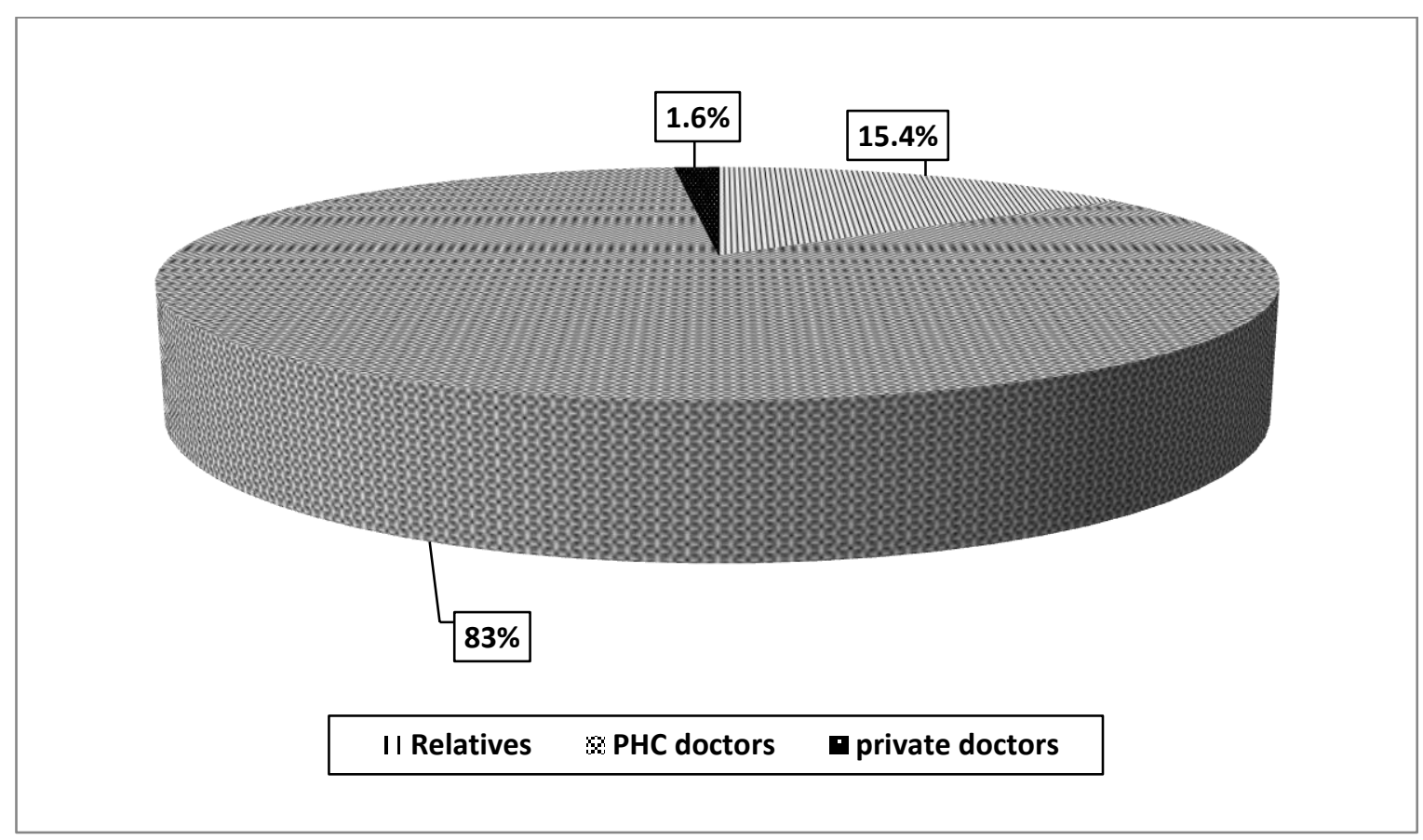

Fig (3): source of the previous knowledge of the females about items of motherhood 